METAgraphias: letra M (MANIFESTOS) v.4 n.1 março| 2019 CAMINHO dos OSSOS • Maria Eugênia Matricardi (m.eugeniamatricardii@gmail.com)

\title{
CAMINHO dos OSSOS
}

Maria Eugênia Matricardi ${ }^{1}$

${ }^{1}$ Maria Eugênia Matricardi é doutoranda em Poéticas Transversais na Universidade de Brasília, educadora e artista visual. Pesquisa performances, políticas estéticas e epistemologias do sul na América Latina. 
METAgraphias: letra M (MANIFESTOS) v.4 n. 1 março| 2019 CAMINHO dos OSSOS • Maria Eugênia Matricardi (m.eugeniamatricardii@gmail.com)
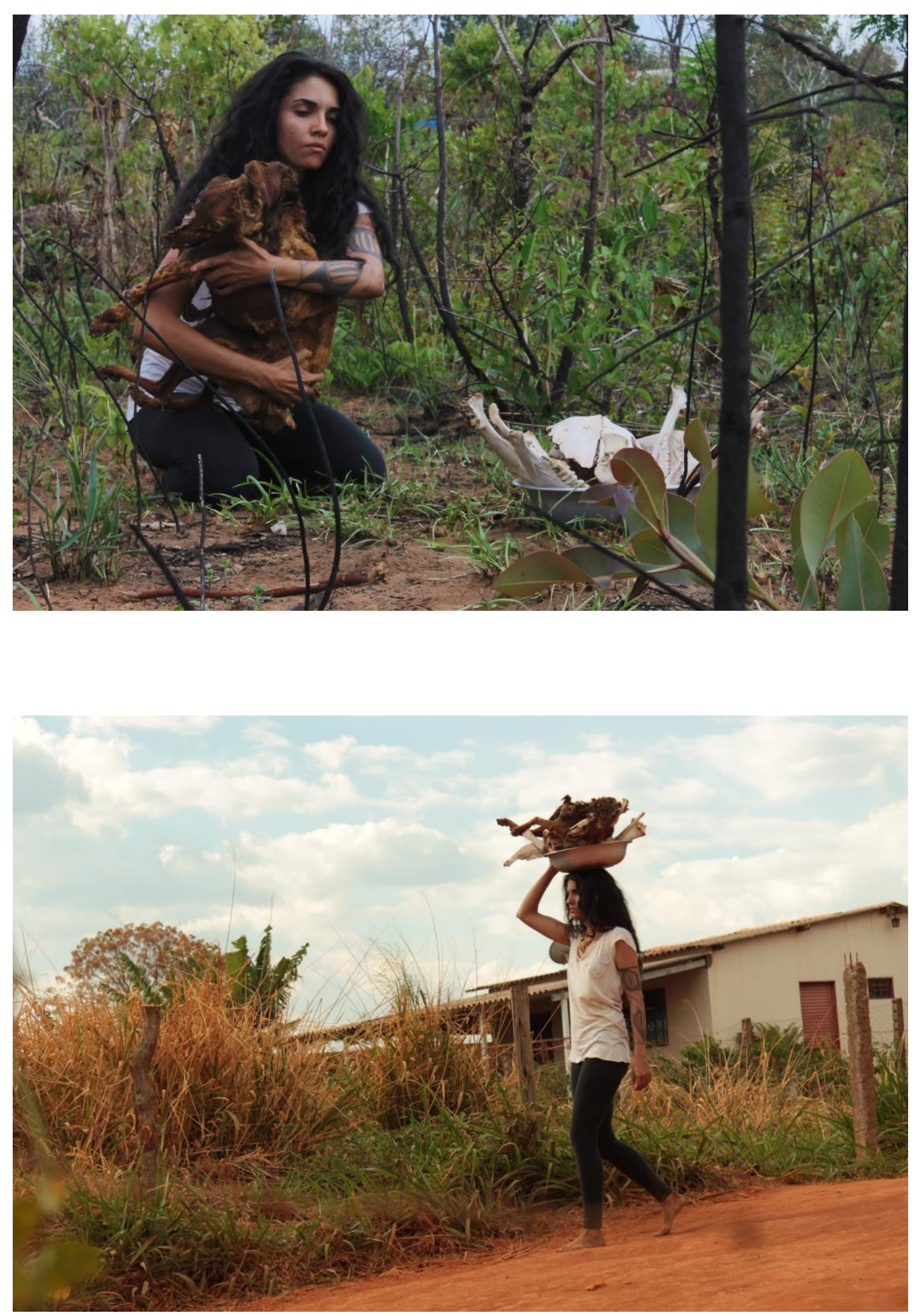
METAgraphias: letra M (MANIFESTOS) v.4 n.1 março| 2019

CAMINHO dos OSSOS•Maria Eugênia Matricardi (m.eugeniamatricardii@gmail.com)
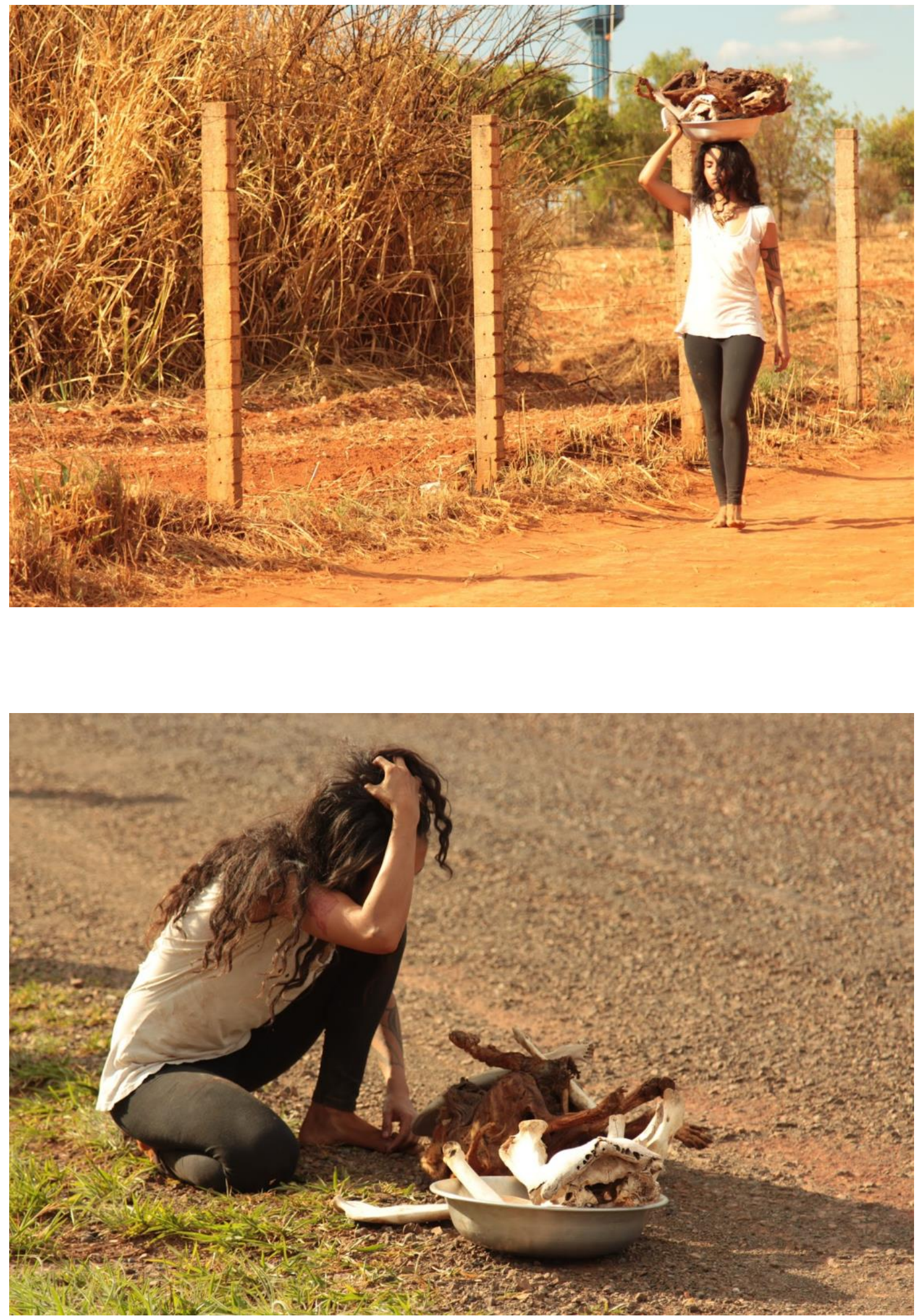
Ação

Título: Caminho dos Ossos.

Ação realizada por: Maria Eugênia Matricardi.

Tempo de duração: aproximadamente 3 horas.

Local: Lago Oeste-DF.

Materiais utilizados: colar de dentes de cachorro e vacas mortas encontradas na beira da estrada e bacia de alumínio.

Fotos: Jackson Marinho, John Stoppa e Rômulo Barros.

Videomaker: Bruno Corte Real.

Produção: Corpos Informáticos.

Evento: Participação, performance e política- PPP 2016.

Prêmio: $1^{\circ}$ Edital Redes FUNARTE. Evento Participação, Performance e Política 2016.

Disponível em: http://performancecorpopolitica.net

Resumo: A escrita, fragmentada, traz na própria transtemporalidade a performatividade promíscua entre as referências da literatura, ação em artes visuais, antropologia, filosofia contemporânea e das ciências sociais, que ora transita por um lugar tradicionalmente reconhecido como acadêmico, ora se reconhece como devir em movimento nos ensaios poéticos, trazendo-nos para a fratura das diferentes linguagens e dos conceitos, dos contos e da construção da escrita como outro objeto estético que não se prende à mera descrição das ações evocadas. A terceira margem do rio, imagem-conceito a partir do conto de João Guimarães Rosa surge como fratura do tempo, risca terceira, produção de desvio no corpo social. Édouard Glissant se faz presente a partir de conceitos como poética das relações, rastro/resíduo, crioulização e pensamento do tremor.

Palavras-chave: terceira margem, poética das relações, ações. 
Minha casa é o cão de rua que não é meu, que apenas acontece de estar ali...

Ana Martins Marques

Encaboclamento esse, de pisar chão em pele escutando o vento. Desatino; movimento de busca sem objeto. Vestiu o rosto de urucum, o corpo de sol e o olhar de exclamações silenciosas a cada fragmento de horizonte que apanhava.

Beira de estrada. Poeira vermelha impregnada no vento, ventre, entre os dedos do ora sol ora chuva que faz rebrotar as folhas das árvores-carvão. Cerrado: contorcido, carbônico, controverso nas suas angulações e asperezas. A poeira dança, esses passos desnecessários abrem alas à vaga do não sabido.

De tarde, sol, pele, poeira, urucum ardem em vermelho. Reluz, branco e seco, de uma feiura bonita a mandíbula de uma vaca morta. Dentes largos, ossos, fragmentos de um mugido, de uma carne que não existe. Outra mandíbula, não era sabida a anatomia e o encaixe desse bicho. Chifres em uma cara de olhos fundos sem olhos com fratura no meio da testa; seria essa a geografia do acidente? Isso, do estranho acometido, imanta as intenções. Queria sair dali, mas qual incômodo em casa de família a gente não sabe como se despedir. Acocorada ante os ossos, não sabendo se por vontade xôxa ou ataque de vida válida (ROSA, 2001) foi resolvido, aliás, não se resolve o que te atravessa, se fracassa e pronto, de pegar os ossos no colo e refazer o caminho de volta à chácara.

A vespa carrega uma aranha morta. A aranha peluda, maior em peso e tamanho em pelo menos três da vespa segue arrastada no seu desacordamento. Rastro de dez ou quinze metros na superfície vesparanha traduzidos em um imaginário torpe de medidas como uma dezena de quilômetros.

Crateras, deserto vermelho, cascalhos-meteorito deformando o caminho, patas pontiagudas afundando a terra: compartilhamos o mesmo devir. Ossos no colo arrastando morte em beira de estrada. Entreolhares se reconhecem: estavam fazendo a mesma coisa. Os ossos, a aranha, nós em comunhão enquanto diz a vespa sem ver o caminho tecido de costas: escuta o fracasso no silêncio do mundo, ele desdiz o caminho avesso onde não há certo.

Na bacia de alumínio com água a escova lambe o que fica do corpo da vaca. É preciso conviver 
com essa matéria para deslembrar ativamente (MUIANGA, 2015). Os negros e negras antes de partirem d'África eram obrigados a darem 7 e 9 voltas em torno de um baobá. Nas palavras de Leda Maria Martins:

Sinédoque e metáfora do corpus territorial e cultural africanos, esse baobá testemunha espetacularmente $\circ$ vigor das fundações e raízes africanas e a permanência de seus textos, mesmo quando atravessados pelo palimpsesto do outro. Na complexidade de sua textualidade oral e na oralitura da memória, os rizomas ágrafos africanos inseminaram o corpus simbólico europeu e engravidaram as terras das Américas. Como o baobá africano, as culturas negras nas Américas constituíam-se como lugares de encruzilhadas, intersecções, inscrições e disjunções, fusões e transformações, confluências e desvios, rupturas e relações, divergências, multiplicidade, origens e disseminações. (MARTINS, 1997, p.25)

Esquecer desfazia a possibilidade de amaldiçoar. A possibilidade de amaldiçoar desfazia $\circ$ esquecimento. No útero-porão navio negreiro, a gênese da crioulização (GLISSANT, 2013) cultural, já tão mesclada e reconfigurada na Poética das Relações (GLISSANT, 2013) redimensionava o pensamento do tremor (GLISSANT, 2014) de tal forma que "O atlântico foi-se tornando o epicentro de uma nova concatenação de mundos, o lugar de onde emergiu uma nova consciência planetária." (MBEMBE, 2014, p.31). Os ossos do mundo guardam essa delicadeza: deslembram parte da matéria para não nos deixar esquecê-la, há sempre o que fica.

Param, mesmo diáspora, mesmo movimento, paradoxalmente imutáveis no centro do segredo. Huellas. Rastro/Resíduo (GLISSANT, 2013). De.com. posição.

Chapéu de palha, pés no chão, capanga de lona e uma selvagem compostura. Amanhece o desejo de uma arqueologia imprecisa, busca por uma imagem, hipótese inexistente. Os pés sentem a quentura cascalhenta da estrada. Vida descalça. Crianças brincam com o lixo queimando. Pedaço de pau com plástico na ponta, as gotas incandescentes perpetuam o fogo enquanto exala o cheiro da fumaça tóxica, o som da chama plástica vem da tecnologia da traquinagem, sem ontologia definida. A roça é desnorte. Vendo o lixo, um fêmur, no meio da diversão delas. Acenou com o chapéu. Os olhares das crianças fitaram com curiosidade. Acordo firmado, a cerca de arame farpado é atravessada, a peça cálcica do quintal pula para dentro da capanga. Uma aparição em troca de um fêmur. Nada disseram, tudo se escuta.

Um homem de carro oferece carona. Sol a pino. Segue poeira na negativa. Um velho gordo desponta horizonte em riba de um cavalo branco encardido. 
- Ocê quer carona?

- Sim senhor.

- Mas ocê quer mesmo?!

- O senhor não ofereceu? Estou aceitando...

- Vou encostar o cavalo no barranco, ocê pula.

Em um salto, o flanco do bicho é alcançado de primeira. Segue trotando. A perplexidade surge na falta do desajeito.

- Vi uma moça lá atrás dentro de um buraco com uma cama dentro. Amiga sua?

- Amiga sim...

- O quê que ocê tá fazendo?

- Coletando ossos. Sabe onde eu poderia encontrar mais?

Silêncio.

Na capanga: um fêmur mais quatro mandíbulas encontradas.

- Acho que nessas beiras de mato ocê encontra...

Trota bestamente o cavalo calmo.

- Onde cêfica?

- Aqui mesmo moço.

Testemunha de coisa incerta ou coisa alguma consumada, nem o velho nem o cavalo questionaram. É que nesses casos indiscutível não se discute. Desnorte esse da roça, acolhendo todos os desvios.

Era beira de outra estrada. Por conseguinte uma via rápida, rodovia perpendicular que atravessava o Lago Oeste. Placa amarela: DEVAGAR: ANIMAIS NA PISTA. Na beira da beira da estrada, na beira do rural e do urbano, mato adentro embrenhado. Uns metros de cautela apontam cheiro de carniça. Que corpo seria aquele? Fedia desproporcionalmente ao seu tamanho. Costelas aparentes, meia pata osso, meia pata couro ensebado com restos de pêlo. A cara sorria com caninos e arcada dentária à mostra. Despudorado. Não, seria demais, excedia os limites do demasiado. Conviver com essa catinga expunha coisa desarrazoada à qual a gente prefere não dar nome. Ele só rindo da dúvida. Os dentes rangiam ao convite ensurdecedor. A morte ri da nossa cara o tempo inteiro sem nos darmos conta da piada, trapaceira. Arqueologia do futuro essa. Se por força de acaso ou potência de vida, ela foi nele ter conversa.

Coisa de se acocorar na frente desembestada. Chapéu de palha arredado para chegar à periferia dos olhos. No canto do olho tem um saco grande de milho sem milho para as galinhas. Meio de 
mato é esconderijo para rejeitos. O cão, de certo atropelado na vagabundagem que ousava atravessar o progresso. Jogado além da sarjeta, ○ mato camufla o terrível espetáculo onde pendulam corpos frágeis. Asfalto, carros rápidos, cicatriz civilizatória cortando paisagem. A rodovia é longa, cravada de cruzes anuncia cemitério nômade onde tombam mendigos, prostitutas, animais, crianças de bicicleta e vagabundos de estrada.

Às vezes tombam também as carcaças metálicas que cospem fumaça, capotadas fragilmente diante de seu próprio canibalismo. Um assovio, o cachorro vagabundo pula para dentro do saco, se sente feliz com a viagem.

Omolú é a terra quente que recebe os corpos mortos. Transmutação que nos encaminha ao Orum. Dono da praga, da doença e da cura. Conhece os feiticeiros e as bruxas. Ele nada pede, a não ser o corpo para que seja devorado. Rei que nasceu com o sol, pai do vermelho. Rei do corpo, da morte e da vida. Sob o manto de palha ele guarda os segredos. Em sua cabaça traz axé e feitiço. Terra. Atotô.

Cabelos longos, negros, pés no chão impregnados de terra sol. A palha do chapéu cobre a cabeça de mistério. Era uma mulher fazendo o caminho de volta. Carregava um saco nas costas, uma capanga de lona cheia de ossos de vaca e cheiro de cachorro morto, fiel companhia.

Dentro do saco os ossos do cão chacoalhavam no vagar calmo da mulher da beira da estrada. Uma sutil sinfonia tilintava entre a capanga de ossos da vaca e o cachorro no saco. $O$ cheiro, incomensurável. Uma mulher passa de carro oferecendo carona dizendo o caminho sofrido por sem sombra e chão fervendo. Ela não sabia do cheiro pelos metros de distância, se soubesse esse convite se fazia desatino, certamente. A presença viva do cão nunca mais deixaria aquele carro, impregnando cada molécula do estofado com sua catinga. A figura de saco nas costas e bolsa no ombro faz um gesto, rejeita gentil a gentileza e segue estrada. Pensaram as bolhas dos pés: melhor criar cascos, faz parte do processo. Se furtava a seguir a alhures.

Sentada no mato, desfiava fibras de sisal. Amarrou os fios no dedão do pé enquanto esticava linha para amarrar os dentes. Os pequenos dentes do cão se alternavam com a quadratura dos dentes da vaca. Quanto menores mais escultóricos e detalhados.

Raízes com três pontas, caninos afiados e uma escova para limpá-los depois de arrancar um a um da arcada com alicate. Cada dente era um filho ao qual dedicava cuidado: estranho-familiar. Horas de trabalho delicado fazendo surgir um colar primitivo, desses objetos genuínos, bonito pela 
honestidade que carrega. Ancorava na fileira de dentes amarrada ao pescoço uma relação disruptiva com um tempo-sem-tempo, atravessado por muitas camadas. Transtemporalidade semlugar, reticências em imaginários desnacionalizados. Velas, ebós, cachaça na encruzilhada. Corpo compartilhado avançando em sombra-luz, parada, na clareira do mato. Cosmopolítica xamânica na ecosofia do cerrado. Dedicava-se a domar ossos.

Abriu-se terceira margem (ROSA, 2001). Dessas fraturas onde cintilam luzes vacilantes - no conto $A$ terceira margem do rio de Guimarães Rosa, do livro Primeiras Estórias - o rio, sempre em movimento, convida o pai a uma deriva subjetiva sem explicação.

Nosso pai não voltou. Ele não tinha ido a nenhuma parte. Só executava a invenção de se permanecer naqueles espaços do rio, de meio a meio, sempre dentro da canoa, para dela não saltar, nunca mais. A estranheza dessa verdade deu para estarrecer de todo a gente. Aquilo que não havia, acontecia. (ROSA, 2001, p.80)

Um dia ele manda fazer para si uma canoa e parte a parte alguma, sem nunca estacionar em nenhuma margem. Nem seguia para longe, nem permanecia no não-encontrável, avulso, segue sem seguir na perenidade do tempo a qual ele perfura com sua canoinha de nada. Era pessoa tranquila desde sempre; quieto, cumpridor de seus afazeres e responsabilidades, abandona todas as suas referências e permanece impávido próximo ao seu habitat, absolutamente fora dos hábitos. Deforma a estrutura social ao seu redor, de forma que todos se veem obrigados a reformular sua realidade sensível e material. Rosa inscreve nesta imagem um gesto conceito sem conceito por via do grito silencioso.

Escutamos terceira margem do rio, na composição de Caetano Veloso e música de Milton Nascimento:

Oco de pau que diz:

Eu sou madeira, beira

Boa, dá vau, triztriz

Risca certeira

Meio a meio o rio ri

Silencioso, sério

Nosso pai não diz, diz: 
Risca terceira

Água da palavra

Água calada, pura

Água da palavra

Água de rosa dura

Proa da palavra

Duro silêncio, nosso pai

Margem da palavra

Entre as escuras duas

Margens da palavra

Clareira, luz madura

Rosa da palavra

Puro silêncio, nosso pai

Meio a meio o rio ri

Por entre as árvores da vida

O rio riu, ri

Por sob a risca da canoa

O rio viu, vi

O que ninguém jamais olvida

Ouvi, ouvi, ouvi

A voz das águas

Asa da palavra

Asa parada agora

Casa da palavra

Onde o silêncio mora

Brasa da palavra

A hora clara, nosso pai

Hora da palavra

Quando não se diz nada 


\section{Fora da palavra}

\section{Quando mais dentro aflora}

Tora da palavra

Rio, pau enorme, nosso pai

Oco de pau diz sem dizer. Triztriz risca terceira, na linha do rio, margens paralelas, a canoa risca a água que se apaga em movimento. Escritura ágrafa que se faz rio, dissolvida em silêncio. $\mathrm{O}$ gesto do pai rasga o real de estarrecimento pela radicalidade do insólito, um golpe de permanecer sem voltar, terceira margem da a-significância, fora da palavra, gesto sem-tempo que atravessa sem comunicar. Invocadas as instituições sociais de controle, padre, soldados e jornalistas para convencer aquele senhor da canoa de voltar à família, ele segue remando no incabido, para fora de uma realidade cartografada no mapa das representações conhecidas. Rio profundo, puro silêncio devir água firmado entre o filho e o pai, pai e rio, rio adentro. Água, margem, asa, brasa da palavra imaterial de Rosa, homenageado por Milton e Caetano. Não temos explicações plausíveis, nessa estória, que pelo título do livro renega o caráter histórico da verdade, a relação da ficção constitui outros devires. Realidade como construções de narrativas ficcionais, aos modos da terceira margem arte-vida na partilha do sensível (RANCIÈRE, 2009).

A fratura da terceira margem se dá no tempo, um acontecimento psíquico que nos aproxima da vibratilidade (ROLNIK, 2006) na intimidade muda da subjetividade que exerce $\circ$ indizível. O tempo acontece no corpo, na decisão desarrazoada onde a racionalidade fracassa.

Segundo Achille Mbembe, de forma frequente na literatura africana, o devir negro do mundo (MBEMBE, 2014) atravessa as imagens como corpo fragmentado, instaurando uma desterritorialização poética na qual a linearidade temporal não se faz projeto subjetivo. A escritura surge a partir do corpo, do empilhamento de ossos, da diáspora, das experiências de guerras atravessadas por um universo enfeitiçado, (des)velando outras camadas de realidade, habitando partes incertas da existência na poética das relações (GLISSANT, 2013).

[...] a crítica do tempo tal como se desenrola na ficção negra contemporânea ensina-nos igualmente que o tempo é sempre aleatório e provisório. Vai mudando indefinidamente, e as suas formas são sempre incertas. Consequentemente, representará sempre uma região heterogénea, irregular e fragmentada da experiência humana. (MBEMBE, 2014, p.209-210)

O tempo linear, acreditado ingênua e violentamente dentro da perspectiva da modernidade 
fracassa. Ele deixa de ser uma abstração evolutiva à qual o conceito de raça se desenvolve em um abismo infinito, onde bárbaros seriam absolutamente incapazes de alcançar racionalmente, sensivelmente e economicamente a estrutura civilizatória. A transtemporalidade fecunda da literatura e oralitura negra descoloniza imaginários, aglutinando, em sua multiplicidade suas durações não simultâneas e seus fluxos.

Em A triste história de Barcolino, o homem que não sabia morrer, de Lucílio Manjate, autor moçambicano, a morte, apresentada como lugar difuso e desassossegado intersecciona os avessos do impreciso, da ficção e disrupção do real,

da certeza frágil de habitar um tempo presente que convive com um passado encarnado em um corpo que não desaparece: “Tio Barco! O senhor ainda está vivo?" pergunta o sobrinho a Barcolino, "O que você acha? - respondendo Barcolino, olhando o fundo dos olhos do afilhado, e sorria com uma ironia cadavérica. Estava mais alto, magro e muito escuro" (MANJATE, 2017, p.25). As dúvidas do insólito perpassam o corpo enquanto experiência sensível, o jogo entre o que se vê e os lugares de sensações: "Desde que cheguei ainda não me vi - explicou", segue a narrativa na casa do afilhado; "Diante do espelho, tive um susto de morte. O homem ao meu lado, de carne e osso, era a própria magumba no reflexo. Quilos de peixe a ofegar na arritmia das guelras. O olhar líquido e ausente, era triste”. (Idem Ibid, p.30). De certa forma, a escrita literária negra contemporânea parece mergulhar na face noturna por via do desamparo (SAFATLE, 2015), despossessão predicativa onde as formas dadas do corpo-cadáver são resignificadas em devir, 0 poder se torna força de germinação, e a morte, lugar de cura e diferença.

Tempo-sem-tempo dentro da carcaça do cão. Com uma colher cavava o oco dos ossos cobertos por uma pele seca e engordurada. Vísceras não haviam, a não ser a visceralidade do gesto empenhado. Era uma dança: padê pas de deux movimento relação. Retirava restos de pele, vermes secos emagrecidos de sol e charque. Chega uma hora em que até mesmo os vermes morrem, não é mesmo?

O cão sorria banguelo balançando o cotoco do rabo. $O$ couro com alguns poucos pêlos cor de burro fugido se esticava sobre a carcaça até onde podia, falia em alguns momentos deixando o vazio exposto. Ele ficava deitado, sol a sol em cima de um formigueiro, fuçava a terra em busca de companhias que pudessem devorá-lo. Cedia de si para alimento, se tivesse órgãos os doaria, mas como não tinha, compartilhava o pouco que lhe sobrava. Mania de vagabundo que divide dois dedos de cachaça com três a toas ou mais. Arruado, magro e maltrapilho, vivia de comer 
constelações e forrar a cama de poeira.

Alto funcionário das maiores disfunções, ele abanava as moscas com o cotoco do rabo e mordia o vento em câmera lenta fingindo ameaça àquelas que pousavam nas suas costas sarnentas, tudo mentira, sabiam que era facilitador e acabava fazendo vista grossa aos pousos no aeroporto do seu focinho. Esse sem olhos que chora na expectativa de uma nova jornada sentia falta de duas coisas: da baba que escorre pelo canto da boca, matéria pegajosa dos reparos afetivos a cada lambida, e, da terceira margem daquela estrada, rumo ao não sabido.

Chegado o dia da viagem, a mulher descalça prepara bacia de alumínio, veste o colar de ossos e escangalhos de roupa em elegância indomesticada. Na bacia ela empilha crâneos, mandíbulas e fêmures. O cão cheira sem olfato os ossos, acena com o rabo, late em silêncio, ofegante e ansioso despende a ausência de língua pra fora e deita sobre a cama dura. Laroyê! Sendo o próprio movimento e senhor dos caminhos ela pede primeiro licença a Exu. Se ajoelha aos ossos: saluba Nanã! mojubá minha mãe, senhora dos pântanos, matéria viva em putrefação, dona do jardim dos mortos. Atotô Obaluaiê! Atotô pai. Braços de rio abraçam o cão em profundidade. A carniça unge os trapos dela, entranha na pele. Exalosa, ela segue constante em seu exílio interior junto as suas companhias.

Sem rodilha na cabeça, ela carrega a bacia distribuindo o peso pela sua coluna vertebral. Em riba, os ossos na moleira, abaixo, a terra passo a passo, andar de carroça lenta partindo o sol com os pés. Havia escutado uma vez que o mesmo cálcio que forma os ossos habita a matéria frágil e explosiva das estrelas, fato científico de comprovada alquimia, se sentia parte do mundo para além da crosta, corpus cósmico profuso, caótico. Era dada a sutis estranhezas, e, de caso com poesia, decidia dar convívio a de todo inconvivível: a peçonha das cobras, os rastros brilhantes de lesmas nas pedras, os espinhos caídos dos galhos de árvores e cascas de ovo de passarinho avoado.

Na terceira margem ela segue estrada. Mãos suadas de esforço brotando água na secura da paisagem. Linhas de arame farpado à direita do caminho delimitam o espaço. Quase ninguém ao redor traz solitude aos passos. Mato cortante, caliandras, pequizeiros e árvores sem nome, casas distantes sem gente na varanda. Terra lavrada com milharal esturricado. Os passos seguem lentos e ofegantes. Não havia utilidade alguma no que fazia, por isso abria vaga ao não entendimento qual acontecia. Desse ataque de vida válida (ROSA, 2001) se fazia disposta, andarilha impertinente, um pé na frente outro em seguida. Segue rumo se equilibrando na linha vermelha do horizonte que divide $\circ$ céu da terra. Poucas nuvens acima em uma luminosidade amarelada 
despejando a distância do azul. Sem dúvidas, sem pergunta e sem razão flui risca terceira nos passos apagados por vento em poeira, rastro/resíduo (GLISSANT, 2013).

Adiante desponta um amontoado de gente. Um boteco ordinário, sertanejo no autofalante dos carros, sinuca de homens sem camisa. Cerveja gelada, sol quente no lazer da quitanda. Os viralatas da rua de terra ecoam seus latidos em prosa com o cão em sua cama de ossos logo acima da cabeça da mulher da estrada. O cheiro pretérito anuncia a presença daquela aparição. Fazendo a curva da rua, ela atravessa o fim de tarde no centro da roça. As mulheres fazem manicure na soleira da porta para escapar do calor das telhas de amianto. Tudo segue em reticência, exclamação e interrogação muda. Nada dizem com a boca. Os olhares disfarçam o desnudar do imprevisível. Ela segue com a bacia catinguenta, cruza a gente, pés terra-terra a caminho do asfalto.

Uma caçamba de lixo, o vrummm dos carros rápidos abre vácuo ao cortar vento. Proa de canoa cortando rio em nau-bacia. O cão rema com ossos no sem destino da terceira margem (ROSA, 2001). Ela se despede dos amigos, devolve a carcaça fedorenta do companheiro no visível da rodovia, para fora de onde tinham sido jogados, o mu das vacas calmas se empilham longe de qualquer esconderijo. O norte dos carros permanece atônito com a visita inesperada no deslembramento ativo (MUIANGA, 2015) dos corpos frágeis. A placa baobá amarela diz constante dos animais e devires da estrada: DEVAGAR: ANIMAIS NA PISTA. Desfazem o pensamento de sistema (GLISSANT, 2013) desterritorializando o asfalto em pensamento arquipelar (Idem), sempre frágil, impreciso e ambíguo, resistem precisamente por sua resiliência e multiplicidade. Os ossos do mundo dizem silenciosamente.

\section{Referências}

GLISSANT, Édouard. Introdução a uma poética da diversidade. Tradução Enilce do Carmo Albergaria Rocha. Juiz de Fora: Gallimard/Editora UFJF, 2013. Tradução de Introduction à une poetique du divers.

.O pensamento do tremor. La cohée du lamentin. Tradução Enilce do Carmo Albergaria Rocha e Lucy Magalhães. Juiz de Fora: Gallimard/Editora UFJF, 2014

ROLNIK, Suely. Geopolítica da cafetinagem. In: Núcleo de estudos da subjetividade. Disponível 
em:http://www.pucsp.br/nucleodesubjetividade/Textos/SUELY/Geopolitica.pdf. Acesso em: 08 agosto de 2018.

MARTINS, Leda Maria. Afrografias da memória: O Reinado do Rosário de Jatobá. São Paulo: Perspectiva; Belo Horizonte: Mazza Edições, 1997.

MANJATE. Lucílio. A triste história de Barcolino, o homem que não sabia morrer. São Paulo: Editora Kapulana, 2017.

MBEMBE, Achille. Crítica da razão negra. Tradução de Marta Lança. Lisboa: Antígona, 2014.

MUIANGA, Aldino. O domador de burros e outros contos. Série Vozes da África. São Paulo: Editora Kapulana, 2015.

RANCIÈRE, Jacques. A partilha do sensível. Estética e política. Rio de Janeiro: Editora 34, 2009. ROSA, João Guimarães. Primeiras Estórias. Rio de Janeiro: Editora Nova Fronteira, 2001.

SAFATLE, Vladimir. 0 circuito dos afetos: corpos políticos, desamparo e o fim do indivíduo. São Paulo: Editora Autêntica, 2015.

\section{Música}

Caetano Veloso (letra) e Milton Nascimento (música). Álbum Circuladô. 1991. Tempo: 2:23 min. 